\title{
A System Dynamics-Based Model For Demand Forecasting In PPP Infrastructure Projects - A Case Of Toll Roads
}

Rajaa Alasad

School of Built Environment, Heriot-Watt University, Edinburgh, UK

ra280@hw.ac.uk

\author{
Ibrahim Motawa \\ School of Built Environment, Heriot-Watt \\ University, Edinburgh, UK \\ i.a.motawa@hw.ac.uk
}

\author{
Stephen Ougunlana \\ School of Built Environment, \\ Heriot-Watt University, Edinburgh,UK \\ s.o.ogunlana@hw.ac.uk
}

DOI 10.5592/otmcj.2013.3.4 Research paper

\section{Keywords}

Causal Loop Diagrams, System Dynamics, Toll Roads
The success of Public Private Partnership (PPP) infrastrucTURE PROJECTS IS HIGHLY DEPENDENT ON THE DEMAND FOR THE SERVICES PROVIDED BY THESE PROJECTS. THE DEMAND FORECASTING PROCESS IS COMPLEX BECAUSE OF THE INFLUENCE OF VARIOUS ECONOMIC, SOCIAL AND TECHNICAL FACTORS AND THE INTERRELATIONSHIPS AMONG THEM. In addition, this process is dynamic in nature as many of these factors are time dependent. Current models used for demand forecasting have failed to account for many of these aspects. Among various modeling techniques, System Dynamics (SD) is a promising method for modeling systems with complexity and dynamicity features. The modeling process using SD can be broadly divided into Qualitative System Dynamics and Quantitative System Dynamics. This paper describes the development stages of a conceptual Qualitative SD model for demand forecasting which include: factors identification, creating Causal Loop Diagrams (CLDs), and the CLDs validation. As expert knowledge and perceptions are key requirements to develop a realistic SD model, the paper will emphasis on the knowledge elicitation involved in the development stages. The paper articulates different approaches used to collect and analyze perceptions solicited from experts in toll road projects and the demand forecasting discipline in order to build this qualitative model. In addition, it depicts how the information has been integrated into the different stages of the modeling process. The developed qualitative model will form the basis for the development of the quantitative SD model aiming at improving the practices of demand forecasting in PPP toll road projects. 


\section{INTRODUCTION}

Decisions related to financial and technical aspects of infrastructure transportation projects in general and toll roads in particular, are mainly based on future demand forecasting. Therefore, the feasibility study of any of these projects entails forecasting the expected demand for services offered by the facility in question. Achieving the desired accuracy of projections is challenging. Several studies in the area of demand forecasting have highlighted and proved the presence of variation between forecasted and actual demand in toll road and other transportation projects (Morgan (1997), Bain and Plantagie (2004), Bain and Polakovic (2005), Bain (2009), Flyvbjerg et al. (2003) and (2005), Engle el al. (2003), Li and Hensher (2010), and Welde and Odeck (2011)). For instance, Bain (2002) has explored 32 toll road projects all over the world. The projects included bridges, highways and tunnels. The study illustrated that actual traffic volume for 28 projects was less than the projections. This core sample was extended to include 104 international PPP toll road projects in 2005 . The main results regarding the discrepancy between actual and forecasted traffic volume did not change. The range of ratios of actual/ forecast is between $86 \%$ below predicted and $51 \%$ above predicted (Bain, 2009). Such variations in these kinds of projects have significant impacts on the overall scheme viability. The World Bank (2008) reported that unrealistic forecast is a major reason for most toll road failures (cited in Li and Hensher, 2010). Moreover, Engel et al. (2007) cited inaccuracy in demand forecasting as the major reason for transportation project distress in the United States. Trujillo et al. (2000) noted that while PPP is being increasingly employed to deliver infrastructure projects, there is growing evidence of non-appreciation of demand forecasting in formulating the partnership agreement. They added that it is not unusual that project partners allocate larger budget to construction studies than to demand estimations; a ratio averaging one to five has been quoted. While excessive effort was made to prove the presence of actual/ forecast demand variations, research related to this area rarely emphasizes the demand forecasting process itself: the focus is mainly on outcomes rather than method.

Quinet (1998) categorizes the sources of inaccuracy in demand forecasting as the following: inadequacy of model structure, inaccuracy of current data and the uncertainty of prediction of future value of exogenous variables. In addition, a study by Flyvbjerg et al. (2005) shows that there are two main reasons for errors in traffic forecasting; namely: technical mistakes in the methodology and the strategic behavior of the bidders. Moreover, Niles and Nelson (2001) identified uncertainty in model design and structure as one of the reasons for forecasting errors. They suggest improving the current models by integrating new variables or designing new models for demand forecasting.

Conventionally, the typical methods employed for demand forecasting can be widely classified into statistical and artificial intelligence methods. While most of the former cannot accommodate interrelations between factors, artificial intelligence methods can. However, the large amount of data required for model development in the latter is still a source of concern.

Demand forecasting models need to account for a variety of qualitative and quantitative factors such as economic growth, population growth, public acceptance, willingness to pay, level of fee and others. Many of these factors are dynamically inter-dependent making demand forecasting a complex system. Therefore, a demand forecasting tool which can efficiently manage the complexity and dynamicity of the demand system is a necessity. SD is a promising method which can account for complex interrelations among dynamic system variables. Nevertheless, the possibility of applying SD to analyze this dynamic and complex system has yet to be fully investigated.

The SD modeling process includes two main phases: Qualitative System Dynamics (or model conceptualization) and Quantitative System Dynamics. While the former is mainly to create cause-effect diagrams, the latter is devoted to quantitative computer simulation. The development of the Qualitative SD involves eliciting relative knowledge from experts and stakeholders to identify and validate the system structure and behavior. To capture this relevant knowledge, a variety of approaches has been employed such as questionnaire surveys, interviews and workbooks. The purpose of this paper is to describe the procedures followed and the approaches employed to develop a qualitative SD model for demand forecasting in toll road projects. This qualitative model will form the basis for the development of the quantitative SD model aiming at improving the practices of demand forecasting in toll road projects. The model application can be expanded to be used for PPP transportation projects in general owing to the large similarity of demand influencing factors in other PPP transportation projects.

The next section of this paper briefly introduces the system dynamics modeling method. The following sections discuss the development of the SD model including the methods used to elicit experts' understanding of the complex aspects of demand. Then, the conclusions will be finally derived.

\section{System Dynamics}

SD is a mathematical and diagrammatical modeling technique that is employed to treat problems of complex nature through building and rebuilding of the system structure. Several phases with a variety of activities are involved in SD model design and development. 


\begin{tabular}{|c|c|c|c|c|}
\hline Randers (1980) & $\begin{array}{l}\text { Richardson and } \\
\text { Pugh (1981) }\end{array}$ & Robert et al (1983) & $\begin{array}{l}\text { Wolstenholme } \\
\text { (1990) }\end{array}$ & Sterman (2000) \\
\hline Conceptualization & $\begin{array}{l}\text { Problem } \\
\text { Identification }\end{array}$ & Problem definition & \multirow{4}{*}{$\begin{array}{l}\text { Diagram } \\
\text { conceptualization } \\
\text { and analysis } \\
\text { Simulation phase } \\
\text { (1) }\end{array}$} & Problem articulation \\
\hline Formulation & $\begin{array}{l}\text { System } \\
\text { Conceptualization } \\
\text { Model formulation }\end{array}$ & $\begin{array}{l}\text { System } \\
\text { conceptualization } \\
\text { Model } \\
\text { Representation }\end{array}$ & & $\begin{array}{l}\text { Dynamic hypothesis } \\
\text { Simulating Model }\end{array}$ \\
\hline \multirow[t]{3}{*}{ Testing } & $\begin{array}{l}\text { Analysis of model } \\
\text { behavior }\end{array}$ & Model behavior & & $\begin{array}{l}\text { Formulation } \\
\text { Testing }\end{array}$ \\
\hline & Model evaluation & & & \\
\hline & Policy analysis & Model evaluation & \multirow{2}{*}{$\begin{array}{l}\text { Simulation phase } \\
\text { (2) }\end{array}$} & \multirow{2}{*}{$\begin{array}{l}\text { Policy formulation } \\
\text { and evolution }\end{array}$} \\
\hline Implementation & $\begin{array}{l}\text { Model use or } \\
\text { implementation }\end{array}$ & $\begin{array}{l}\text { Policy analysis and } \\
\text { model use }\end{array}$ & & \\
\hline
\end{tabular}

Table 1. System dynamics modeling process across the classic literature (Luis et al., 2004)

Different frameworks for a system dynamic-based modeling process have been identified as shown in Table 1. Despite this discrepancy in dividing the modeling process into several stages, the main activities constituting the whole modeling process are generally the same.

According to the prevailed SD modeling process developed by Sterman (2000), this modeling process is divided into five stages which will be adopted to develop the proposed demand forecasting model. The first two stages concern Qualitative System Dynamics (model conceptualization) while the other three stages constitute Quantitative System Dynamics. The former stages are mainly to identify the problem and to create Causal Loop Diagrams (CLDs) which is the main purpose of this paper, the latter is devoted to quantitative computer simulation.

According to Sterman (2000), SD modeling is an iterative process of problem structuring, quantitative modeling, testing and refinement to define the major factors and relationships governing system behavior. Experts of the application field should identify the problem structure as they have more in-depth and comprehensive understanding of relevant information. In the transportation sector, experts should possess wide knowledge and detailed information regarding the reasons behind and the impact of demand variations and its complexity and dynamicity. Forrester (1992) identified three kinds of knowledge sources which can facilitate the creation of SD models, namely; numerical, written and mental. Among these three types of knowledge sources, Forrester argues that mental models are the richest.

Knowledge extracted from the mental models of the stakeholders of a system can be drawn from individual experts or from a panel of experts. While focus group is the most common method to elicit information from a group of experts, several other methods are also used to elicit information from individuals such as questionnaires, interviews, and workbooks (Vennix et al., 1990).

To develop the proposed SD-based demand forecasting model, several sources of information and corresponding data collection methods have been considered as will be illustrated in the following sections.

\section{SD Modeling Process and Knowledge Elicitation}

SD is a method which can deal with complex and dynamic aspects of a system. The demand forecasting process is complex due to the variety of its influences (economic, social and technical) and their interrelations. In addition, it is a dynamic process due to its strong dependence on time (e.g. demographic changes over time will have its impact on demand volume) and its mutual causal structure (i.e. feedback loops).

Most of the knowledge required to develop system dynamics models exists in the mental models of system stakeholders (Forrester, 1992). Therefore, knowledge elicitation from its sources requires engaging participants from the real system to capture the relevant information necessary to build a reliable model.

In any interactive modeling process, at least two issues need to be recognized, namely the participant in the modeling process and the elicitation knowledge techniques (Vennix and Gubbels, 1992). For the proposed system, the experts incorporated in the modeling process are 


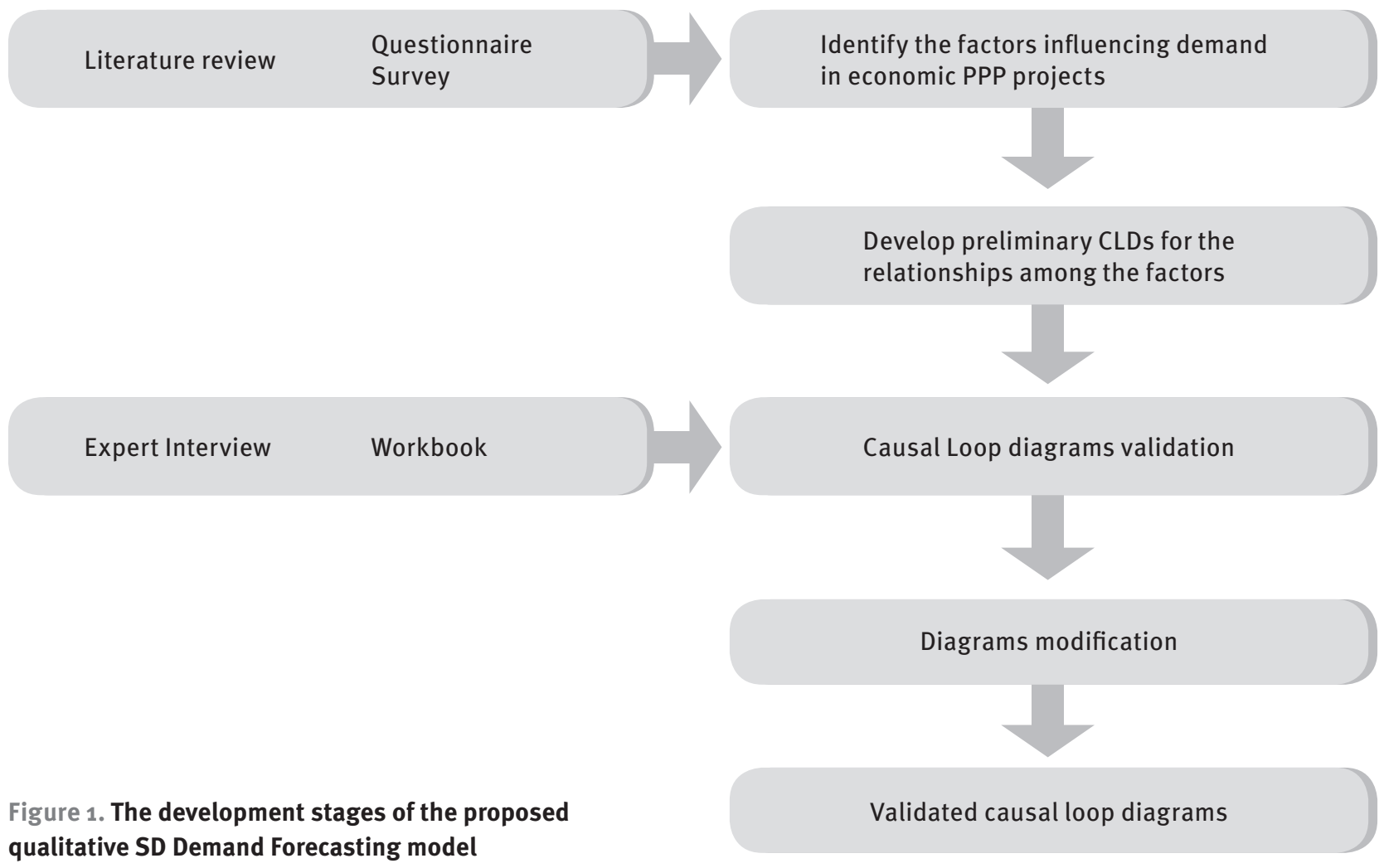

from different backgrounds; those employed in occupation related to toll roads or toll roads demand forecasting discipline. In this context, the experts were selected on the basis of availability and of their extensive experience of working in the relevant field. It was expected that they have an in-depth knowledge about the major reasons behind demand variations, the impact on users, the interest of public and private partners, and the potential actions to alleviate the negative consequences of variation. Stakeholders' understandings and perceptions about the model elements, structure and behavior form a valuable input for the SD model development process. Figure 1 presents the main stages and activities involved in creating and validating the causal loop diagrams for the demand forecasting model. The following sections discuss each of these stages in order to develop the final conceptual qualitative model.

\section{Factors Identification}

Based on the factors' nature and relationships indicated in the problem identification, the model has been conceptualized and documented in an elaborated manner. Model building in SD begins with listing those factors that have a major influence on the output. Various approaches have been recognized to identify those influences such as observation, discussion, interviews and existing data (Forrester, 1992). Sterman (2000) recommends accessing stakeholder databases and written databases when identifying a problem. A written database is a significant source of data since it contains both mental data and interpretations for other sources of information (Forrester, 1992). Therefore, for the model in question, analyzing the available written data was the main source for listing these influences. An in-depth literature review was carried out to identify all relevant factors likely to affect demand in transportation projects and to be included in the preliminary model. In addition to the literature review, the factors identification process included emailing questionnaires to various stakeholders of toll road projects. Open-ended questions were used aiming at (1) ranking the significance of the identified factors based on a thorough literature review (2) identifying other factors to be included and (3) generating causal relationships. This approach of employing questionnaire as a method of knowledge elicitation from individuals, especially when the experts are geographically dispersed, is corroborated by Vennix et al. (1990, 1992).

Therefore, the main factors affecting demand in toll road projects have been identified under certain sub-models for the proposed SD model, which are: socio-economic, the level of fee, willingness to pay, public acceptance and supportive facilities. The factors have been classified to allow the mapping of these factors using SD technique, further details about the classification can be found elsewhere (Alasad et al., 2011). 


\section{CLDs Development}

Dynamics hypothesis is the causal relationships among system elements expressed in CLDs. CLDs are visual representations of the interactions and feedback loops among different factors affecting demand which help in capturing the source problems (Andi and Minato, 2003). This representation constitutes the basis for the subsequent phase in which a computer simulation model will be developed.

The CLDs, representing the hypothesis of the model, depict how each factor can affect the model outcome directly or through other intermediate variables as well as the effect that one variable has on others. They show clearly the direction and kind of causality among different variables in the system (Love et al., 1999). A relationship between two variables $\left(x_{1}\right)$ and $\left(x_{2}\right)$ is represented by an arrow. For each relationship, the link between the two variables is noted as positive if an increase in the variable at the tail of the arrow $\left(\mathrm{x}_{1}\right)$ causes an increase in the variable at the head $\left(x_{2}\right)$. This relationship is noted as negative if an increase in $\left(x_{1}\right)$ causes a decrease in $\left(\mathrm{x}_{2}\right)$. One significant aspect of SD causal diagram is the feedback loop. The presence of feedback loops is the characteristic which gives the system its dynamic nature (Meadows and Robinson, 1985). Feedback loops can be positive or negative. While variables in the positive (or reinforcing loop (R)) increase or decrease indefinitely, variables in the negative (or balancing loop (B)) stabilize over time.

Creating the causal loop diagrams is a key stage in the system dynamics modeling process. In light of the steps and instructions provided by Richardson's guidelines (1991) for building causal loop diagrams, the causal loop diagrams of factors influencing demand in toll road projects have been created. Drawing the CLDs requires identification of the factors affecting demand which form the core of the system. In addition, this process requires understanding of the relationships between those factors which describe the behavior pattern over time. The justification of any of these causal relationships can be done through direct observation, reliance on accepted theory, hypothesis and assumption, and statistical evidence (Coyle, 1996). Thus, the diagrams were developed by listing the influencing factors and then linking these listed factors. For each of these links, the relationship was indicated as positive in the case of the same variation for both connected factors and negative for the contrary case. In addition, the feedback loops were identified and labeled.

The main benefit of developing CLDs is that these diagrams constitute the platform for developing the stock and flow diagrams in the simulation part of the modeling process. However, before the CLDs can be converted into stock and flow diagrams, they need to be validated by the experts in the studied field (i.e. transportation) which is explained in the following section.

\section{CLDs Validation}

Literally, a system can be defined as a collection or group of interrelated elements, forming a complex whole. In other words, the term system relates to the real world or some features of the reality. Thus, model validation is a fundamental part of the model development process to ensure that the model adequately represents this reality.

The proposed causal loop diagrams were validated by experts and professionals in toll roads and toll road demand forecasting discipline. Due to time limitations and experts' commitment, it was difficult to form an expert panel and arrange for a combined meeting for all the experts involved in the validation process as was originally planned. However, the experts were approached individually. A series of semi-structured interviews with six experts in toll roads and demand forecasting areas were conducted. Each of these meetings began with a preliminary depiction of the research aim and objectives, a general overview of system dynamics as an adopted methodology, and the expected meeting outputs. The interviewees were then asked to review each of the demonstrated diagrams to: (1) add or drop variables (cause, effect, or intermediate), (2) verify the existence and direction of each relationship in the diagram and (3) point out any missing relationships.

The abovementioned questions aiming at CLDs validation cover the eight categories for legitimate reservation suggested by Goldrate's Theory of Constraints (Dettmer, 1997). The main aim of these categories is to identify the criteria that determine the validity of CLDs. These criteria include clarity, quantity existence, cause sufficiency, additional cause possibility, predicted effect existence, tautology (Question 1 and 3), connection edge existence and cause-effect reversal (Question 2 and 3) (Burns and Musa, 2001).

During the course of the meeting, the relative significance of the factors and relationships among factors were discussed. The interviewees identified new variables to be included in the model as they indicated that some intermediate factors were missing and they needed to be added to a number of CLDs. In addition, refinements to several relationships were suggested. Knowledge elicitation by stakeholders' interviews proved to be an effective approach to collect data necessary to model conceptualization (Sterman, 2000) as it helped elicit the participants' understanding and capture their views and remarks related to the model under consideration.

This method of employing a preliminary model then engaging the experts in the more advanced stage of creating the CLDs (rather than the case where one starts from scratch) is supported by several SD researchers such as Hart 
et al. (1985), and Morecroft and Heijden (1992). It helps reduce the time invested by the participants and, at the same time, enhance the contribution of the participants in developing the conceptual model (Vennix and Gubbels, 1992).

In addition to the conducted interviews, a workbook was prepared and emailed to other experts who were difficult to interview because of their tight schedules. The workbook contains the CLD diagrams representing the model structure and detailed descriptions of the causal relationships. The participants' perceptions were sought regarding the level of agreement or disagreement with each of the modeled factors and relationships. Using this method of knowledge elicitation is supported by Vennix (1996).

Based on the results of the whole interviews and by revisiting, comparing and combining the interviewees' comments, the diagrams have been further refined and updated to develop the validated causal loop diagrams constituting the conceptual model. The conceptual model of the demand forecasting model consists of many cause-effect diagrams. However, due to space limitations, only Socio-economic and willingness to pay cause-effect diagrams are presented in this paper.

\section{Validated CLDs}

Figures 2 and 3 show the validated CLDs for the Socio-economic and willingness to pay sub-models of the conceptual SD demand forecasting model.

The Socio-economic causal loop diagram suggests many feedback loops. The first one is a reinforcing loop $\mathrm{R}_{1}$ where the economic growth in the facility area will trigger more job opportunities, attracting more labor to this area, which consequently will increase the level of demand. However, continuous increase in demand resulting from more

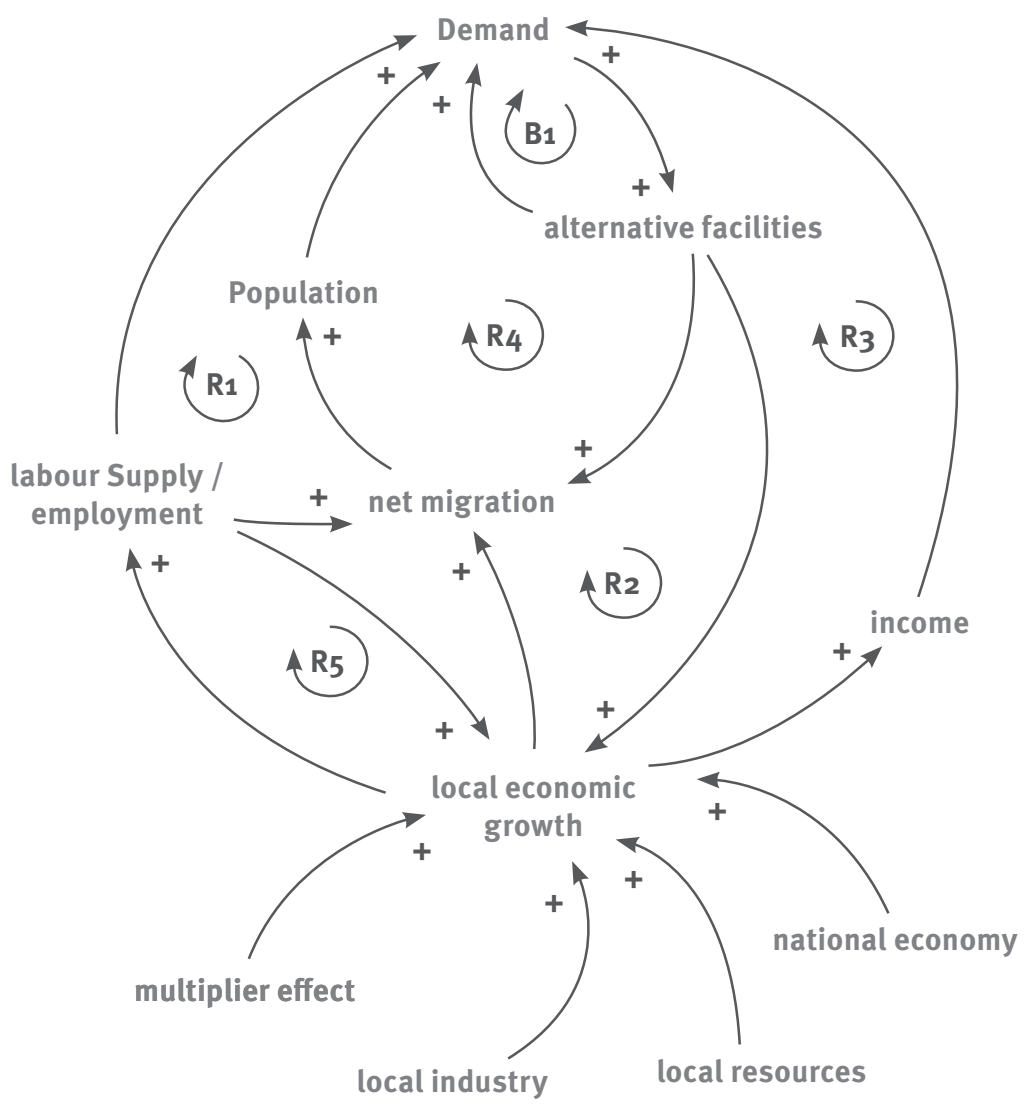

Figure 2. Causal Loop Diagram of the 'Socio-economic' sub-model

job opportunities will create a need for another facility to relieve inordinate pressure on the initial one. This new built project will eventually contribute to the economic growth. However, it should be noted that constructing another facility in the area is highly likely to negatively affect the demand for the service provided by the facility in concern ( $B_{1}$ loop). The second reinforcing loop, R2, suggests that economic growth will enhance migration to the facility area which increases the population growth that finally results in demand growth. The R3 loop suggests that economic growth will help increase income levels leading to a further increase in the purchasing power of potential users which will eventually have its positive impact on the level of demand. $R_{4}$ is the final reinforcing loop where the newly constructed facility (alternative facility) will help attract migration to the facility area, causing population growth and consequently increase in demand. In addition, the diagram suggests that there are many exogenous factors affecting economic growth such as national economy, local resources, local industry and multiplier effects.

The willingness to pay causal loop diagram suggests one balance loop (B1). In addition the diagram shows that there are a set of factors which positively affect willingness to pay for the service provided. Those factors include quality of service, historical experience of paying for similar service, benefits from using the facility, income and user wealth. On the other hand the diagram shows that the level of fee negatively affects user's willingness to pay.

The developed CLDs form the basis of developing the quantitative SD model for demand forecasting in toll road projects. The proposed SD model will overcome the main deficiencies of the existing models by considering different qualitative and quantitative factors and the complex relationships among them and by accounting for the dynamicity of those factors. 


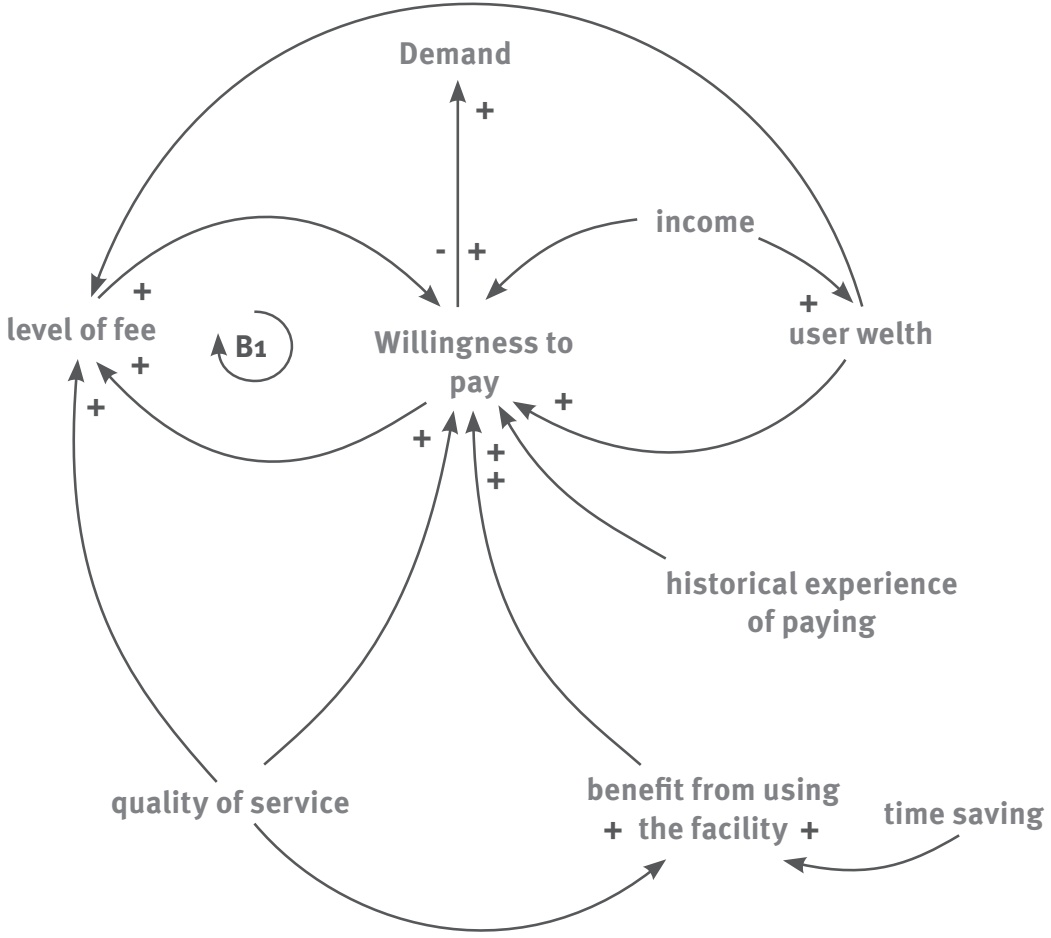

Figure 3. Causal Loop Diagram of the 'Willingness to Pay' sub-model

\section{Conclusions}

The SD modeling process includes several activities in which the system stakeholders are of paramount importance. This paper presented a structured method to elicit the knowledge from these stakeholders at the model development stage. A variety of data collection approaches were integrated. Besides the written database, a questionnaire survey was distributed to list the main factors affecting demand. The set of factors constituted a starting point for model conceptualization by creating CLDs. Since modelers often create relationships intuitively, the CLDs need to be validated. This process entailed eliciting relevant knowledge from the experts' mental model. For the CLDs validation, the knowledge elicitation process was based on a combination of face-to-face interviews and e-mailed workbooks. The interviewees were asked to evaluate the diagrams and to offer suggestions for modification. The information elicited from the experts was distilled and combined

\section{References}

Alasad, R., Motawa, I. and Ogunlana, S. (2011), "Identifying Demand Risk in Public Private Partnership (PPP) in Infrastructure projects”, In: Akintoye, A., Liyanage, C. \& Renukappa, S., eds. CIB TG72/ ARCOM Doctoral Research Workshop Public Private Partnership, 12th October 2011 University of Central Lancashire, Preston, UK. 134.

Andi and Minato, T. (2003), “Representing causal mechanism of defective designs: a system approach considering human errors", Construction Management and Economics, 21, 297-305.

Bain, R. (2009), “Error and Optimism Bias in Toll Road Traffic Forecasts". Transportation, 36(5), 469-482.

Bain, R., and Polakovic, L. (2005), "Traffic Forecasting Risk Study Update 2005: Through Ramp-Up and Beyond". Standard \& Poor's, London.

Bain, R, and Plantagie, J. W. (2004), "Traffic forecasting risk study updates 2004 ". Standard \& Poor's, London.

Bain, R and Wilkins, M. (2002), "The Credit Implications of Traffic Risk in Start-Up Toll Facilities", Standard \& Poor's, London.

to produce a set of validated CLDs to constitute the basis for the quantitative modeling stage. The next stage of the research will permit the implementation of the model in a computer modeling tool and undertake the simulation process. The proposed SD model will help improve the efficiency of the forecasting process by overcoming the current models shortfalls through the inclusion of different qualitative and quantitative influences, tracing the dynamicity of those influences, and accounting for the complex relationships among them.
Barlas, Y. and Dalkiran, E. (2008), “Testing Dynamic Decision Making Under Real-Time Pressure: A Scuba Diving Simulator”. In: 2008 International Conference of the System Dynamics Society.

Burnes, J. and Musa, P. (2001), "Structural Validation of causal loop diagrams", SD conference. Atlanta.

Coyle, R. G. (1996), System Dynamics Modelling, A Practical Approach, London, Chapman \& Hall.

Dettmer, H. W. (1997), “Goldratt’s Theory of Constraints: A Systems Approach to Continuous Improvement”, Wisconism, ASQ Quality Press.

Engel, E, Fischer, R. and Galetovic, A. (2007), "The Basic Public Finance of Public-Private Partnerships”, NBER Working Paper, No. 13284. Last updated January 2011.

Engel, E, R. Fischer, R and Galetovic, A, (2003), "Privatizing Highways in Latin America: Fixing What Went Wrong," Economia, 4(1), 129-158.

Flyvbjerg, B. (2007), “Cost overruns and demand shortfalls in urban rail and other infrastructure", Transportation Planning and Technology, 30. 
Flyvbjerg, B., Holm, M. K. S. and Buhl, S. R. L (2005), "How (In)accurate Are Demand Forecasts in Public Works Projects?The case of transportation", Journal of the American Planning Association, 71 (2), pp.131-146.

Flyvbjerg, B., Bruzelius, N. and Rothengatter, W. (2003), "Megaprojects and risk: An anatomy of ambition”, New York: Cambridge University Press.

Forrester, J. W. (1992), "Policies, decisions and information sources for modeling”, European Journal of Operational Research, 59, 42-63.

Hart, S., Boroush, M., Enk, G. and Hornick, W. (1985), “Managing complexity through consensus mapping: Technology for the structuring of group decisions". Academy of Management Review, 10: 587-600.

Love, P., Mandal, P. and Li, H. (1999), "Determining the causal structure of rework influences in construction", Construction Management and Economics, 17, 505-517.

Li, Z. and Hensher, D. A.(2010), "Toll Roads in Australia: An Overview of Characteristics and Accuracy of Demand Forecasts", Transport Reviews. 30, 541-569.

Luna-Reyes, L. F. and Andersen, D. L. (2003), "Collecting and analyzing qualitative data for system dynamics: methods and models", System Dynamics Review, 19, 271-296.

Meadows, H. and Robinson. J. (1985), The Electronic Oracle: Computer Models and Social Decisions, Chichester.

Morecroft, J. D. W. and Van Der Heijden, K. A. J. M. (1992), "Modelling the oil producers - Capturing oil industry knowledge in a behavioural simulation model", European Journal of Operational Research, 59, 102-122.

Morgan, J.P. (1997), “Examining Toll Roads feasibility studies”, Finance. J.18(1), 1-12.

Niles, $\mathrm{H}$ and Nelson, D. (2001), "Identifying Uncertainty in Forecasting of Travel Demand" Available at http://www. globaltelematics.com/NilesNelson2001.pdf [Accessed 11 April, 2011].

Quinet, E (1998), Principles d'Economic des Transport, Paris, Economica.

Randers, J. (1980), “Guidelines in model conceptulization, in elements of the System Dynamics methode", MIT Press, Cambridge, 117-139.

Richardson, G (1991), Feedback Thought in Social Science and Systems Theory.Philadelphia, PA, University of Pennsylvania Press.
Richardson, G. and Pugh, A. (1981), "Introduction to System Dynamics: Modelling with DYNAMO", Cambridge, MIT Press.

Roberts, N., Anderson, D., Deal, R., Grant, M. and Shaffer, W. (1983), Introduction to Computer Simulation: A System Dynamics Modeling Approach Reading, Addison-Wesley.

Roy, S., Marg, K. S. K. and Mohapatra, P. K. J. (2000), "Causality and Validation of System Dynamics Models Incorporating Soft Variables: Establishing an Interface with Structural Equation Modelling" In: 2000 system dynamics conference, 2000 University of Bergen, Norway.

Sterman, J. (2000), Business Dynamics: Systems Thinking and Modeling for a Complex World, USA, Jeffrey J. Shelstad.

Trujillo, L., Quinet, E. and Estache, A. (2000), "Forecasting the Demand for Privatized Transport: What Economic Regulators Should Know, and Why" Policy Research Working Paper Series: 2446, The World Bank.

Vennix, J. A. M. (1996). Group Model Building. Facilitating Team Learning Using System Dynamics, Chichester, Wiley.

Vennix, J. A. M. and Gubbels, J. W. (1992), "Knowledge elicitation in conceptual model building: A case study in modeling a regional Dutch health care system" European Journal of Operational Research, 59, 85-101.

Vennix, J. A. M., Gubbels, J. W., Post, D. and Poppen, H. J. (1990), “A structured approach to knowledge elicitation in conceptual model building", System Dynamics Review, 6, 194-208.

Welde, M. and Odeck, J. (2011), “Do Planners Get it Roght? The Accuracy of Travel Demand Forecasting in Norway" EJTIR, 1(11), 80-95.

Wolstenholme, E.F. (1990), System Enquiry: A System Dynamics Approach, John Wiley \& Sons, Chichester. 